\title{
Gastrophysics in the brain and body
}

Per Møller

\begin{abstract}
In this short paper, a few important problems are highlighted that fall naturally within the emerging science of gastrophysics. This paper does not discuss how 'gastrophysics' is similar to or different from 'neurogastronomy' or 'molecular gastronomy'; but just notes that the time seems ripe for problems within these areas, as witnessed by the recent proposals of these as separate 'emergent' scientific fields centered at problems not covered by other traditional scientific disciplines.
\end{abstract}

Keywords: Pleasure, Preferences, Flavour pairing, Quantity vs. quality

\section{Introduction}

In my view, the new field of gastrophysics should include psychological, psychophysical and neuroscientific considerations in order to truly address fundamental problems related to human consumption of foods, no matter whether these are related to questions of pleasure and satisfaction, or are more concerned with health issues [1-3]. These fields, on the other hand, being mostly phenomenological and with very little predicting power, could greatly benefit from inspiration from theory and simulation of complex physical (and other) systems, as exercised mostly by physicists.

At the symposium, The Emerging Science of Gastrophysics (Copenhagen, August 27-28, 2012) Peter Barham suggested that gastronomy relates to gastrophysics in the same way that astronomy relates to astrophysics, the latter explaining the phenomena observed in the former. I fully agree with this view and hope that 'gastrophysics' will provide impetus for less phenomenology and more explanation and prediction in the psychological and neuroscientific areas that deal with food behaviour. In this paper, four groups of problems will be briefly described, which are very open and very relevant to 'gastrophysics'.

\section{It is not all in the brain}

Even though 'flavour is in the brain' [4], many more body and brain processes contribute to hunger, satiety, satisfaction and well-being after a meal [5-7]. A well-

Correspondence: pem@life.ku.dk

Department of Food Science, University of Copenhagen, Rolighedsvej 30, Frederiksberg C DK-1958, Denmark known effect, sensory specific satiety (SSS), describes that 'liking' of a food drops as intake increases and obviously plays a role in controlling the variety of food intake [8-10]. Despite extensive literature on SSS, any precise theory for prediction of 'transfer effects' (from one food to another) or for the number of sensory dimensions necessary to capture the effects has still to be formulated. The same applies to effects of induced sensory specific desire (SSD), which describes the non-random desire for other foods the eating of a given food induces [11]. SSDs might depend entirely on the food culture in which a measurement takes place, thereby being an indication of the strength of 'learning of food preferences'. There might, on the other hand, be elements of universality to SSDs, such that different foods in different cultures with similar sensory profiles will induce the same desires in different cultures. This would be highly interesting because it would demonstrate another level of universality of food preferences than what is usually described.

SSS and SSD are dynamic processes, which are dependent on neural and hormonal systems in the brain and body. At the phenomenological level they lend themselves to analysis by dynamic simulation, but to the best of my knowledge this has not been attempted yet.

\section{Formation of preferences}

All of our food preferences, with the notable exception of preferences for sweetness and fattiness, are learned. The types of learning responsible for food preference change are completely incidental and the memory systems involved are not semantic in nature. Learning takes 


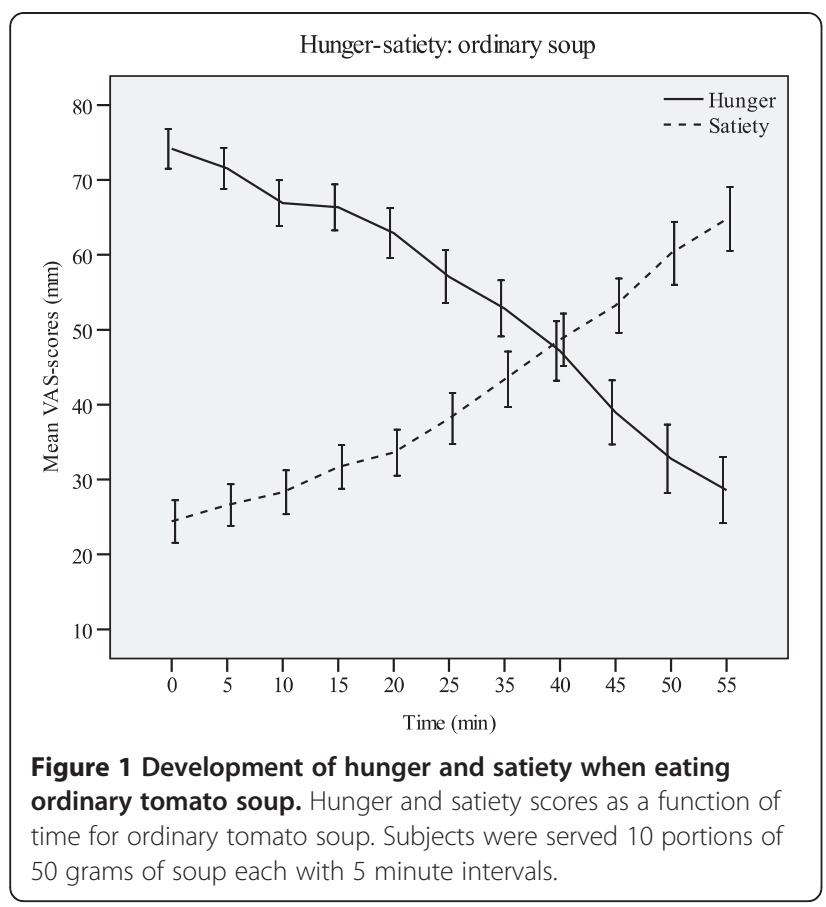

place already in the fetal state $[12,13]$ and a number of conditional learning types have been identified which help us to change our food preferences $[14,15]$. A better understanding of the mechanisms of preference formation has potential for both gastronomy and health. It has been found that children have specific sensitive periods for these types

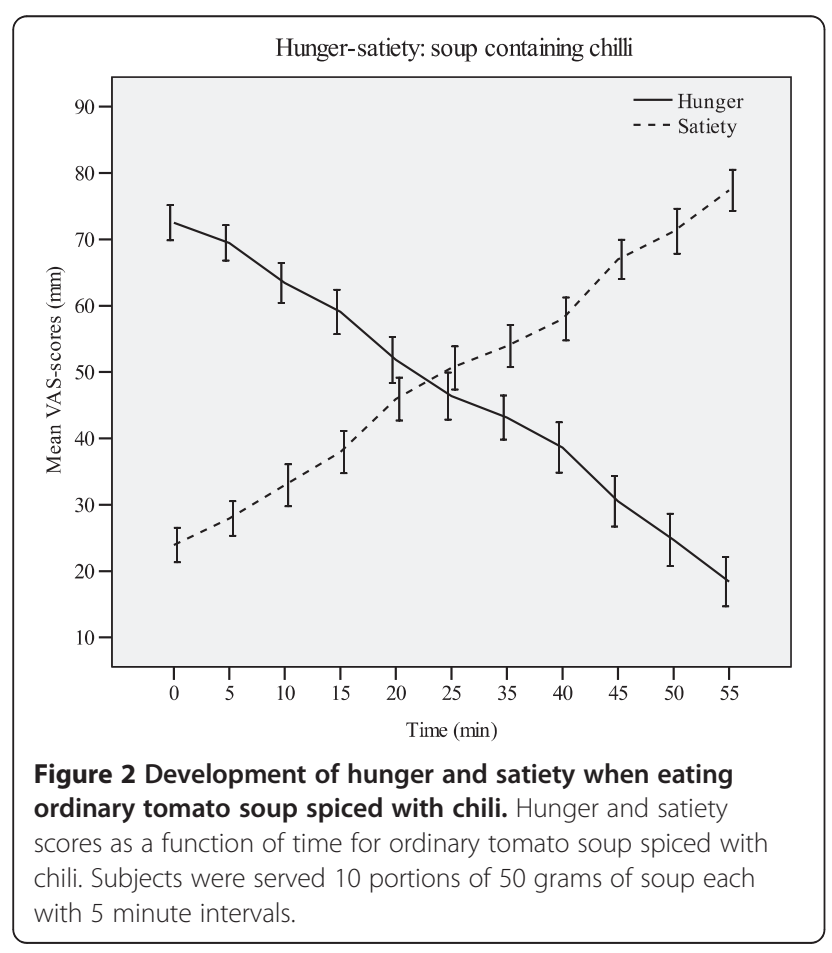

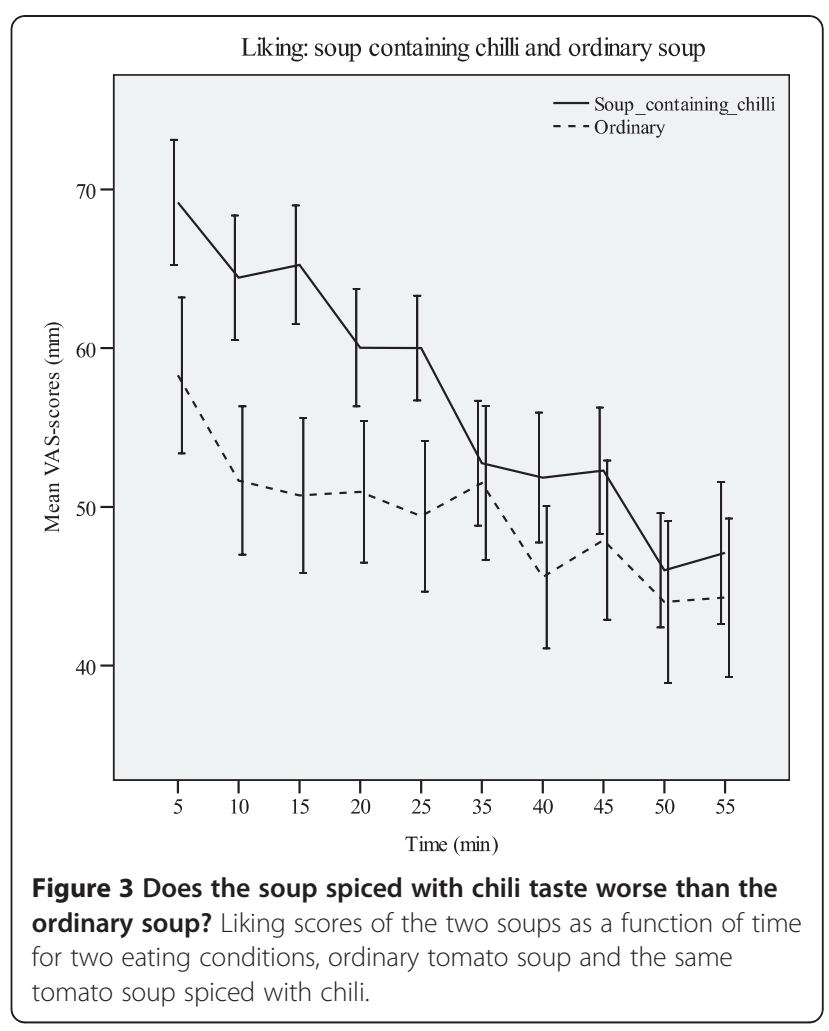

of learning. More information about these mechanisms in adults would be very useful, both from a health and from a food enjoyment or hedonistic perspective. Since it is virtually certain that sustainability concerns imply that we have to dramatically change the foods we eat, a better understanding of the neurobiological mechanisms responsible for preference formation and change could facilitate this necessary change of food habits.

\section{The flavour pairing problem}

Even though a broader approach, including interoceptive states (the sensation of the physiological condition of the body) [16], is necessary to understand food appreciation, there are many important open problems of a less dynamic nature than those experienced during and after a meal, which are almost entirely the business of the brain. Flavour pairing, that is, which flavours will, if paired, produce an experience that is more appreciated than either of the two flavours alone, is one of these problems. Limiting the problem to odours only still presents major challenges. At present, no theory in olfaction can predict the non-linear effects implied in flavour pairing problems. There are many linear curve-fitting schemes available, but none with any power of predicting the interesting non-linear pairing results.

Solving the odour pairing problem would contribute greatly to hedonic psychology and affective neuroscience, 
as well as being a first step towards a less phenomenological science of flavour pairing.

The scientific literature on flavour pairing is surprisingly limited especially given the enormous progress, scientifically as well as commercially, a better understanding of flavour pairing would bring. A hypothesis that two foods that share volatile molecules should go well together has not received support $[17,18]$. Chefs collectively have a very large knowledge base of flavour pairing, which scientists should tap into, from an anthropological, psychophysical and neuroscientific perspective, to physicochemical investigations.

\section{Quantity vs. quality}

Will high gastronomic quality of foods consumed on a daily basis lead to overeating, thereby exacerbating problems of overweight and obesity? This view has indeed surfaced in certain scientific circles [19-21].

It might, to some, seem almost self-evident, but to others, like myself, not at all so. From a highly unscientific introspection and conversations with friends and colleagues about these matters, it seems that most of us eat far less high quality Parmesan cheese when offered it, than cheap, not so tasty hard cheeses. The same applies to wines and chocolate. Very few people can eat a whole $100 \mathrm{~g}$ bar of Valrhona chocolate in one go, but easily perform this feat with chocolate of a lesser quality. From a more epidemiological point of view, one would wonder why the obesity problem in France is less severe than in other affluent countries with foods and meals generally of a lower quality than those served in France.

The question can be phrased as whether it is possible to replace 'quantity' with 'quality'. If this is indeed the case, gastrophysical/neurogastronomic/molecular gastronomic studies of delicious foods might have a major impact on how to tackle problems of overeating.

In an experiment on the effects of trigeminal stimulation (hot spices) on hunger and satiety, Hans $\mathrm{H}$ Reisfelt and I came across a result that is reported in Figures 1, 2 and 3. Subjects in the experiment attended the laboratory twice. On one of the visits they were served an ordinary tomato soup and were asked to report on hunger and satiety feelings, as well as on liking (and other measures which are not important in this context). On the other visit they were served the same base soup but this time spiced with chili.

Figures 1 and 2 illustrate that satiety increases faster and hunger decreases faster when subjects eat the soup spiced with chili. The faster satiation when eating the spiced soup might conceal a wish to stop eating, caused by a lower appreciation of the spiced soup than of the ordinary soup. In Figure 3, however, the opposite effect is seen. Subjects like better the spiced soup that satiated them faster (and more).

\section{Concluding remark}

At the symposium, Erik van der Linden proposed that gastrophysics is not just finding some piece of 'physics' to apply, not just 'physics to go', but new physics, in the broadest understanding of the phrase, needs to be developed. The four sets of problems described all need new fundamental insights and, in my view, fall naturally under the umbrella of 'gastrophysics'.

\section{Abbreviations}

SSD: Sensory specific desires; SSS: Sensory specific satiety.

\section{Competing interests}

The author declares that he has no competing interests.

Received: 7 November 2012 Accepted: 8 November 2012

Published: 9 January 2013

\section{References}

1. Mouritsen OG: The emerging science of gastrophysics and its application to the algal cuisine. Flavour 2012, 1:6.

2. Shepherd GM: Neurogastronomy: How the Brain Creates Flavor and Why It Matters. New York: Columbia University Press; 2011.

3. Barham P, Skibsted LH, Bredie WLP, Frøst MB, Møller P, Risbo J, Snitkjær P, Mortensen LM: Molecular gastronomy: a new emerging scientific discipline. Chem Rev 2010, 110:2313-2365.

4. Small D: Flavor is in the brain. Physiol Behav, in press.

5. Damasio AR: The Feeling of What Happens: Body and Emotion in the Making of Consciousness. Boston, MA: Mariner Books; 2000.

6. Rozin P: Preadaptation and the puzzles and properties of pleasure. In Well-Being: The Foundations of Hedonic Psychology. Edited by Kahneman D, Diener E, Schwarz N. New York: Russell Sage Foundation; 1999:109-133.

7. Berridge KC: Pleasure, pain, desire and dread: hidden core processes of emotion. In Well-Being: The Foundations of Hedonic Psychology. Edited by Kahneman D, Diener E, Schwarz N. New York: Russell Sage Foundation; 1999:525-557.

8. Rolls BJ, Rolls ET, Rowe EA, Sweeney K: Sensory specific satiety in man. Physiol Behav 1981, 27:137-142.

9. Rolls BJ, Rowe EA, Rolls ET: How sensory properties of foods affect human feeding-behavior. Physiol Behav 1982, 29:409-417.

10. Sørensen L, Møller P, Flint A, Martens M, Raben A: Effect of sensory perception of foods on appetite and food intake: a review of studies on humans. Int J Obesity 2003, 27:1152-1166.

11. Olsen A, Ritz C, Hartvig D, Møller P: Comparison of sensory specific satiety and sensory specific desires to eat in children and adults. Appetite 2011, 57:6-13.

12. Schaal $B$, Marlier $L$, Soussignan R: Human foetuses learn odours from their pregnant mother's diet. Chem Senses 2000, 25:729-737.

13. Hausner H, Nicklaus S, Issanchou S, Mølgaard C, Møller P: Breastfeeding facilitates acceptance of a novel dietary flavour compound. Clin Nutrition 2010, 29:141-148

14. Hausner $\mathrm{H}$, Olsen $\mathrm{A}$, Møller P: Mere exposure and flavour-flavour learning increase 2-3 year-old children's acceptance of a novel vegetable. Appetite 2012, 58:1152-1159.

15. Birch LL: Development of food preferences. Annu Rev Nutr 1999, 19:41-62.

16. Craig AD: How do you feel? Interoception: the sense of the physiological condition of the body. Nat Rev Neurosci 2002, 3:655-666.

17. Kort M, Nijssen B, van Ingen-Visscher K, Donders J: Food pairing from the perspective of the 'volatile compounds in food' database. In Expression of Multidisciplinary Flavour Science: Proceedings of the 12th Weurman Symposium, Interlaken, Switzerland. Edited by Blank I, Wüst M, Chahan C. Wädwnswil: Institut of Chemistry and Biological Chemistry; 2010:589-592. 
18. Ahn Y-Y, Ahnert SE, Bagrow JP, Barabási A-L: Flavor network and the principles of food pairing. Scientific Reports 2011, 1:196.

19. Epstein LH, Carr KA, Cavanaugh MD, Paluch RA, Bouton ME: Long-term habituation to food in obese and nonobese women. Am J Clin Nutr 2011, 94:371-376

20. Møller P, Köster EP: Variety and overeating: comments on long-term habituation to food. Am J ClinNutr 2012, 95:981.

21. Epstein LH, Bouton ME: Reply to P Møller and EP Köster. Am J Clin Nutr 2012, 95:982-983.

doi:10.1186/2044-7248-2-8

Cite this article as: Møller: Gastrophysics in the brain and body. Flavour $20132: 8$.

\section{Submit your next manuscript to BioMed Central and take full advantage of:}

- Convenient online submission

- Thorough peer review

- No space constraints or color figure charges

- Immediate publication on acceptance

- Inclusion in PubMed, CAS, Scopus and Google Scholar

- Research which is freely available for redistribution 